SHEs: Conference Series 3 (1) (2020) $37-44$

\title{
Community Based Disaster Management in Indonesia
}

\section{Chatarina Muryani}

Universitas Sebelas Maret

chatarinamuryani@staff.uns.ac.id

\section{Article History}

accepted 31/07/2020

approved 01/10/2020

published 28/10/2020

\begin{abstract}
The purpose of this article writing is to describe and analyze how the implementation of Community Based Disaster Management in Indonesia. This Sources of articles writing were various libraries, including books, journals, regulations and articles on the website. From the literature review, it can be concluded that CBDM has an important role in disaster risk reduction both in Indonesia and in other countries, and CBDM in Indonesia has been implemented but there are still problems: overlapping management, guidance for sustainability and funding.
\end{abstract}

Keywords: Disaster Risk Reduction, Community, Empowerment

\section{Abstrak}

Tujuan penulisan artikel ini adalah untuk mendeskripsikan dan mengkritisi bagaimana Pengelolaan Bencana Berbasis Komunitas di Indonesia. Bahan penulisan berasal dari berbagai Pustaka baik buku, jurnal, peraturan-peraturan maupun tulisan dalam website. Dari hasil kajian Pustaka dapat disimpulkan bahwa PBBK penting perananya dalam pengurangan risiko bencana baik di Indonesia maupun di negara negara lain, dan PBBK di Indonesia sudah dilaksanakan namun masih ada permasalahan tentang tumpeng tindihnya pengelolaan, pembinaan untuk keberlanjutan dan pendanaan.

Kata kunci: Pengurangan Risiko Bencana, Masyarakat, Pemberdayaan

Social, Humanities, and Education Studies (SHEs): Conference Series https://jurnal.uns.ac.id/shes

p-ISSN 2620-9284

e-ISSN 2620-9292 


\section{PENDAHULUAN}

Pada masa-masa awal hanya ada bencana alam yang menyebabkan kerusakan pada kehidupan, mata pencaharian, dan harta benda manusia. Namun perkembangan pesat infrastruktur fisik dan kemajuan teknologi juga telah meningkatkan frekuensi dan jenis bencana. Buatan manusia (kebakaran, kebakaran kimiawi, ledakan bom, kecelakaan di jalan raya) dan bencana biologis (epidemi, SARS) adalah konsekuensi yang tidak diinginkan dari era teknologi saat ini. Faktanya, kerusakan akibat bencana hampir tidak bisa dipulihkan dan tidak bisa ditangani hingga waktu yang sangat lama

Indonesia dengan kondisi geologis, geografis dan kependudukan yang khas, sangat rawan terhadap berbagai jenis bencana. Jika dilihat dari jenis bencana yang pernah terjadi selama 10 tahun terakhir (th 2009 - th 2019) ternyata yang tertinggi adalah bencana hidrometeorologis seperti banjir, uting beliung, longsor, kekeringan. Namun jika dilihat dari daya rusaknya, gempa bumi dan tsunami meskipun jarang terjadi tetapi mempunyai daya rusak yang tinggi. Gambar di bawah ini menunjukkan jumlah kejadian bencana di Indonesia th $2009-2019$

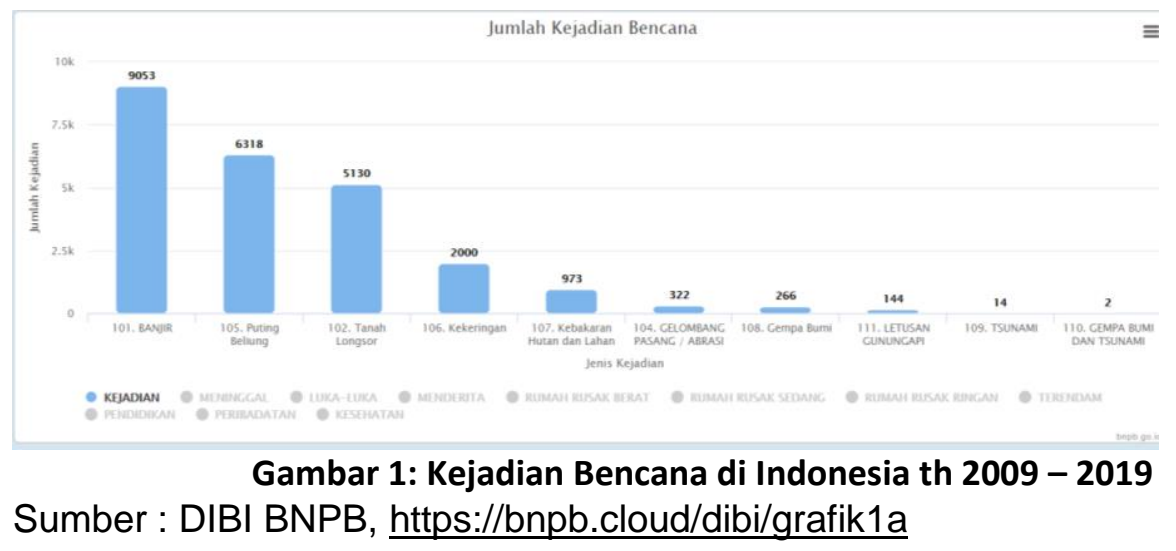

Kejadian bencana, baik disebabkan oleh factor alam maupun manusia, akan berdampak kerugian bagi masyarakat berupa kurban jiwa, harta benda, kerusakan infrastruktur, kerusakan lingkungan dan juga gangguan aktifitas ekonomi. Seringkali pemulihan kerugian-kerugian tersebut berlangsung lama bahkan kadang-kadang tidak dapat kembali seperti kondisi semula. Oleh sebab itu pengurangan risiko bencana mempunyai peranan penting agar dapat meniadakan atau setidak-tidaknya mengurangi dampak negatif dari kejadian bencana.

Dalam pengelolaan bencana seringkali pemerintah cenderung menerapkan pendekatan "atas ke bawah (topdown)" dalam perencanaan manajemen bencana di mana kelompok sasaran diberi solusi yang dirancang untuk mereka oleh para perencana dan bukannya dipilih oleh masyarakat sendiri. Pendekatan seperti itu cenderung mendekatkan tindakan-tindakan manajemen bencana fisik dibandingkan perubahan-perubahan sosial untuk membangun sumber daya dari kelompok yang rentan (Handayani, 2011).

Pada tahun 2005, the United Nations International Strategy for Disaster Reduction (UNISDR) mengembangkan Kerangka Aksi Hyogo (Hyogo Framework for Action / HFA), 2005-2015, untuk membangun ketahanan bangsa dan masyarakat terhadap bencana. Ini memprioritaskan PRB di tingkat komunitas yang menawarkan cara untuk terlibat dengan komunitas dan membuat mereka mandiri (UNISDR, 2007). 
Konsep dasar penanggulangan bencana berbasis masyarakat di Indonesia dan juga di beberapa negara merupakan upaya peningkatan kapasitas masyarakat dalam mempersiapkan dan menanggulangi akibat bencana. Ini karena pemerintah memiliki sumber daya yang terbatas termasuk sumber daya manusia, pendanaan, peralatan, dan logistik. Oleh karena itu, penanggulangan bencana harus bersifat universal, melibatkan semua pemangku kepentingan, baik pemerintah, swasta, dan masyarakat (MSS Ali, et.all, 2019).

Pentingnya melibatkan masyarakat dalam penanggulangan bencana karena: Masyarakat lokal mengetahui desa mereka dan situasi lokalnya dengan sangat baik dan tidak ada orang luar yang dapat memahami peluang dan kendala lokal sebagaimana yang mereka lakukan; oleh karena itu, mereka perlu dilibatkan dalam mengidentifikasi dan menyelesaikan masalah kerentanan bencana. Masyarakat memiliki kepentingan pribadi dalam menghindari bencana dan merupakan sumber utama sumber daya lokal; Dengan demikian, mereka memiliki motivasi dan kemampuan untuk melakukan aktivitas lokal. Masyarakat secara alami sangat peduli dengan urusan lokal yang menjadi sandaran kelangsungan hidup dan kesejahteraan mereka, sehingga informasi harus dihasilkan dengan cara dan bahasa yang dipahami oleh masyarakat.

Pengurangan Risiko Bencana Berbasis Komunitas (RBBK) adalah salah satu pilar penting dalam upaya pengelolaan risiko bencana saat ini. PRBBK umumnya diterima oleh kalangan ahli bencana karena pendekatan struktural/fisik material semata dan fokus pada kedaruratan serta pendekatan yang top-down, jarang memberikan hasil pada ranah pengurangan risiko bencana (PRB) yang berkelanjutan. PRBBK memberikan jawaban yang mencakup beberapa prinsip seperti efisiensi karena idealnya memiliki biaya transaksi rendah disebabkan ada asupan lokal maksimum dan asupan eksternal minimum. Argumentasinya adalah bahwa ukuran-ukuran keberlanjutan seperti efektivitas, legitimasi (partisipasi), dan kesetaraan (equity) terpenuhi, sehingga menjamin keberlanjutan bila beberapa prosedur yang ditawarkan mampu dipenuhi (Paripurna, ET dan Jannah NM, 2014)

\section{MANAJEMEN BENCANA BERBASIS MASYARAKAT}

Penanggulangan Bencana Berbasis Komunitas (PBBM) telah menjadi istilah yang populer selama beberapa tahun terakhir. Namun, hanya dalam beberapa kasus saja hal tersebut berhasil dimasukkan ke dalam isu kebijakan. Ada dua aspek utama dalam hal ini: Pertama, PBBM menjadi prakarsa lokal, dan tidak disebarluaskan dengan baik. Telah diamati bahwa meskipun terdapat contoh-contoh yang baik tentang PBBM di lokasi tertentu dalam suatu negara, pelajaran ini tidak ditransfer ke bagian lain negara tersebut, juga tidak mencapai negara-negara yang berdekatan di wilayah tersebut. Aspek lainnya adalah karena kurangnya pengakuan atas inisiatif PBBM di tingkat nasional, seringkali sumber daya yang dikhususkan untuk kegiatan ini terbatas. Jadi, dalam banyak kasus, PBBM terlihat diisolasi, dan berbeda dari praktik mitigasi bencana nasional, tidak termasuk dalam kebijakan pembangunan nasional .

Ada beberapa istilah untuk "Community Based Disaster Management" namun semua mengacu dalam satu makna yaitu pemberdayaan masyarakat untuk pengurangan risiko bencana. Menurut Paripurno (2006a), Pengelolaan Risiko Bencana Berbasis Komunitas (PRBBK) adalah sebuah pendekatan yang mendorong komunitas akar rumput dalam mengelola risiko bencana di tingkat lokal. Upaya tersebut memerlukan serangkaian upaya yang meliputi melakukan interpretasi sendiri atas ancaman dan risiko bencana yang dihadapinya, melakukan prioritas penanganan/ pengurangan risiko bencana yang dihadapinya, mengurangi serta memantau dan mengevaluasi kinerjanya sendiri dalam upaya pengurangan bencana. Namun pokok dari keduanya adalah penyelenggaraan yang seoptimal mungkin memobilisasi sumber 
daya yang dimiliki dan yang dikuasainya serta merupakan bagian integral dari kehidupan keseharian komunitas.

Pendekatan Pengelolaan Bencana Berbasis (PBBM) adalah bentuk dasar dari pemberdayaan masyarakat dan mekanisme menyebarkan gagasan dari bawah ke atas. PBBM bertujuan untuk mengurangi dampak dan risiko bencana melalui partisipasi masyarakat yang menempatkan masyarakat sebagai pusat pembangunan (Luna, 2014; Urry, 2011). Karena komunitas adalah sumber daya utama dan aktor garis depan dalam pendekatan berbasis komunitas, partisipasi komunitas dalam pengembangan dan implementasi rencana pengurangan risiko bencana, maka harus dipastikan komunitas mempunyai hak yang memungkinkan komunitas untuk mengadakan kegiatan mencegah, mengurangi dan secara efektif menanggapi stres, guncangan dan kejadian yang berpotensi bencana (O ' Brien \& O'Keefe, 2014).

Menurut Yodmani (2001) dan Haque dan Uddin (2013), pengembangan atau pelaksanaan PBBM harus mempertimbangkan hal-hak sebagai berikut:

1. Masyarakat lokal memiliki peran sentral dalam penanggulangan bencana jangka panjang dan pendek, oleh karena itu fokus perhatian dalam penanggulangan bencana harus tertuju pada masyarakat setempat.

2. Pengurangan risiko bencana adalah dasar dari PBBM; Isi utama dari kegiatan penanggulangan bencana berkisar pada pengurangan kondisi rentan dan akar penyebab kerentanan. Strategi utama untuk pengurangan kerentanan adalah meningkatkan kapasitas komunitas dan sumber daya mereka, serta meningkatkan dan memperkuat strategi penanggulangan mereka.

3. Manajemen bencana harus membangun keterkaitan dengan proses pembangunan masyarakat karena bencana dipandang sebagai risiko pembangunan yang tidak terkelola dan masalah yang belum terselesaikan dalam proses pembangunan. PBBM harus mengarah pada peningkatan kualitas hidup sebagian besar masyarakat miskin dan lingkungan alam.

4. PBBM berkontribusi pada pemberdayaan masyarakat - agar aman secara fisik; untuk memiliki lebih banyak akses ke, dan kendali atas, sumber daya; untuk berpartisipasi dalam pengambilan keputusan yang mempengaruhi kehidupan mereka; dan menikmati manfaat lingkungan yang sehat.

5. Karena masyarakat adalah sumber daya utama dalam PRB, peran dan kepentingan mereka harus diakui. Masyarakat adalah aktor kunci sekaligus penerima manfaat utama PRB. Dalam masyarakat, perhatian prioritas diberikan kepada kondisi kelompok yang paling rentan serta mobilisasi mereka dalam PRB. Masyarakat harus berpartisipasi langsung dalam seluruh proses pengelolaan risiko bencana - dari analisis situasi hingga perencanaan dan pelaksanaan.

6. Pendekatan multi-sektoral dan multi- dan trans-disiplin haruslah terapan. PBBM menyatukan banyak pemangku kepentingan masyarakat untuk PRB dan untuk memperluas basis sumber daya mereka. Institusi tingkat komunitas lokal terhubung dengan tingkat menengah dan nasional, bahkan hingga tingkat internasional, untuk menangani kompleksitas masalah kerentanan. Akibatnya, berbagai pendekatan PRB diterapkan.

7. Pendekatan PBBM adalah kerangka kerja yang berkembang dan dinamis dan oleh karena itu pelaksanaannya harus dipantau, dievaluasi dan disesuaikan untuk memasukkan elemen-elemen yang lebih baru. Pembelajaran dari praktik terus dibangun ke dalam teori PBBM dan berbagi pengalaman, metodologi dan alat oleh masyarakat dan praktisi PBBM terus memperkaya praktik.

Sedangkan menurut Twigg (2006) makna berbasis komunitas dalam PBBK dapat diperluas sebagai berikut: 
1. Adanya partisipasi penuh yang melibatkan pula partisipasi pihak rentan, laki-laki dan perempuan; anak-anak, kelompok lanjut usia, orang-orang yang berkebutuhan khusus, ras marjinal, dan sebagainya.

2. Sinonim dengan bottom-up bukan top-down, partisipasi penuh, akses dan kontrol, pendekatan inklusif sense of belonging terhadap sistem penanganan bencana yang sudah, sedang, dan akan dibangun. Pendekatan top-down pada awal kegiatan memungkinkan untuk dilakukan, namun seiring dengan waktu, masyarakat disiapkan untuk dapat mandiri sehingga mekanisme bottom-up dapat lebih dominan.

3. Menggunakan konsep "dari, oleh, dan untuk" masyarakat dalam keseluruhan proses, di mana masyarakat yang mengontrol sistem dan bukan dikontrol sistem (dalam seluruh sistem PRBBK termasuk pula pada Sistem Peringatan Dini)

Meskipun berbagai program pemberdayaan masyarakat yang terkait dengan mitigasi bencana telah mencapai tujuannya, seringkali program tersebut bersifat jangka pendek, dan masalah keberlanjutan dalam upaya ini jarang ditangani. Pemerintah, nonpemerintah, dan organisasi internasional melaksanakan berbagai program sebelum dan sesudah bencana. Kebanyakan dari mereka sangat sukses selama periode proyek, tetapi secara bertahap berkurang seiring berlalunya waktu. Ada banyak alasan untuk fenomena semacam ini, namun kurangnya partisipasi yang efektif dan peningkatan kapasitas masyarakat lokal untuk membaca program tetap menjadi faktor utama kurangnya keberlanjutan (Pandey and Okazaki, 2005)

Perlindungan masyarakat dari ancaman bencana haruslah dilakukan oleh semua pihak, seperti pemerintah, pekerja sosial, masyarakat, maupun stakeholders lain yang dapat terkait. Hal yang paling mendesak adalah menumbuhkan kesadaran dan kemampuan masyarakat untuk melindungi diri sendiri dari ancaman dan resiko bencana.

\section{PENGELOLAAN BENCANA BERBASIS MASYARAKAT DI INDONESIA}

Jika dibandingkan dengan Jepang yang merupakan negara yang sama rawannya dengan Indonesia terkait bencana, ada beberapa perbedaan signifikan antara manajemen bencana ala Jepang dengan yang ada di negeri ini. Di Jepang semakin sering bencana, semakin terlatih dan semakin baik pola penanganan bencana. Berbeda dengan di Indonesia, meski sering dilanda bencana, akan tetapi kapasitas bangsa ini dalam menanggulangi bencana nyaris belum banyak berubah. Poin penting yang dapat diambil adalah perlunya perubahan paradigma masyarakat Indonesia untuk bergerak secara mandiri dan gotong royong (mempersiapkan diri) bukan berpasrah dan hanya menunggu bantuan tanggap darurat pemerintah dalam menghadapi bencana (Ridwan Herianto dkk., 2015).

Belum ada riset sosial khususnya dari aspek sejarah PRBBK. Adopsi pertama khususnya dalam konteks Gunung api Merapi di Yogyakarta, secara embrionik di mulai sejak tahun 1994 yang diawali dengan membaca perilaku masyarakat Merapi yang selamat dari peristiwa letusan Gunung api Merapi di tahun 1994. Para aktivis di Kappala (Komunitas Pencinta Alam dan Pemerhati Lingkungan) Indonesia kemudian melakukan pembelajaran sendiri dan konseptualisasi sendiri atas kerja-kerja mereka bersama komunitas Merapi. Munculnya istilah CBDM (Community Based Disaster Management) relatif baru dimulai di tahun 1996-1998. Dari persinggungan dengan aktor-aktor PRB internasional seperti Oxfam yang berbasis di Yogyakarta, beberapa tokoh Kappala seperti Dr. Eko Teguh Paripurno dan peneliti di UPN Veteran Yogyakarta, pertama kali menerbitkan buku tentang Participatory Rural Appraisal (PRA) untuk penanggulangan Bencana. Lain halnya yang terjadi di Nusa Tenggara Timur, PRBBK muncul awalnya sebagai sebuah gerakan yang bertepatan dengan 
peristiwa El-Nino di tahun 1998, di mana Pusat Informasi Rawan Pangan (PIRP) memulai pengumpulan informasi serta melakukan berbagai riset-riset sosial untuk menanggapi masifnya respon internasional dan pemerintah dalam hal pengadaan pangan yang justru merusak sendi-sendi pertahanan dan penyesuaian lokal.

Partisipasi masyarakat merupakan faktor kunci dalam merespon bencana. Dalam Undang-Undang Nomor 24 Tahun 2007 tentang Penanggulangan Bencana dan Peraturan Badan Nasional Penanggulangan Bencana No. 13 Tahun 2010 tentang Rencana Nasional Penanggulangan Bencana (Renas-PB) 2010-2014, dan Keputusan Kepala Badan Nasional Penanggulangan Bencana Nomor 5 tahun 2010 tentang Rencana Aksi Nasional Pengurangan Risiko Bencana (RAN-PRB) tahun 2010 sampai dengan 1012 secara jelas menyebutkan pentingnya peran serta masyarakat, LSM termasuk masyarakat internasional. Pelaksanaan partisipasi masyarakat berbasis penanggulangan bencana akan mengarah pada:

a. Pengurangan risiko bencana dengan masyarakat di daerah rawan bencana secara mandiri;

b. Menghindari munculnya kerentanan baru dan ketergantungan masyarakat di daerah rawan bencana;

c. Manajemen risiko bencana merupakan bagian integral dari proses pembangunan dan pengelolaan

d. sumber daya alam untuk kelangsungan hidup di daerah rawan bencana; dan

e. Pendekatan multisektoral, multidisiplin dan multikultural.

Penanggulangan Bencana Berbasis Komunitas di Indonesia semakin diperjelas dengan dikeluarkanya Peraturan Kepala BNPB No 1 Tahun 2012 tentang Pedoman Umum Desa/Kalurahan Tangguh Bencana. Hal ini terlihat pada latar belakang dikeluarkanya kebijakan tentang Desa Tangguh Bencana, yaitu mengingat korban terbesar dari bencana adalah kaum miskin di tingkat masyarakat dan yang pertamatama menghadapi bencana adalah masyarakat sendiri, pemerintah mengembangkan program pengurangan risiko bencana berbasis komunitas, sesuai dengan tanggungjawab negara untuk melindungi segenap bangsa dan seluruh tumpah darah Indonesia sebagaimana diamanatkan dalam Undang-Undang Dasar Negara Republik Indonesia Tahun 1945. Salah satu strategi yang akan digunakan untuk mewujudkan ini adalah melalui pengembangan desa-desa dan kelurahan-kelurahan yang tangguh terhadap bencana. Pengembangan Desa/Kelurahan Tangguh Bencana juga sejalan dengan Visi Badan Nasional Penanggulangan Bencana: "Ketangguhan bangsa dalam menghadapi bencana".

\section{PERMASALAHAN PBBM DI INDONESIA}

Sebagai daerah yang sangat rawan terhadap berbagai jenis bencana, Pengelolaan Bencana Berbasis Masyarakat sangat penting perananya untuk pencegahan (tahap pra bencana), kedaruratan (pada saat bencana) maupun pada tahap pemberdayaan masyarakat untuk rehabilitasi dan rekonstruksi (tahap pasca bencana). Namun demikian masih ada beberapa permasalahan yang perlu dipecahkan agar PBBM di Indonesia dapat dikembangkan secara maksimal. Permasalahanpermasalahan tersebut adalah:

1. Tumpang tindih

Ternyata ada beberapa organisasi baik instansi Pemerintah maupun organisasi swasta yang berinisiasi mengembangkan PBBM dengan nama, skema pembiayaan yang berbeda-beda. Kementerian Sosial RI misalnya, mengembangkan sebuah konsep yang disebut Kampung Siaga Bencana yang dilandasi oleh Peraturan Menteri Sosial Republik Indonesia Nomor 128 tahun 
2011 tentang Kampung Siaga Bencana. Sedangkan BNPB membentuk Desa/Kelurahan Tangguh Bencana berdasarkan Peraturan Kepala BNPB Nomor 1 tahun 2012 tentang Pedoman Umum Desa/kelurahan Tangguh Bencana. Palang Merah Indonesia yang merupakan suatu Lembaga yang sering berkecimpung dalam bidang kebencanaan, juga membentuk relawan Siaga Bencana Berbasis Masyarakat yang disingkat dengan SIBAT. Belum lagi berbagai LSM baik dalam maupun luar negeri juga mengembangkan hal yang sama di daerah sasaran kegiatan mereka. Jika lokasi kegiatan berbeda-beda, hal ini tidak menimbulkan masalah dan justru merupakan pemerataan kegiatan. Namun kadang-kadang satu lokasi Desa/Kelurahan dipakai beberapa kegiatan yang mirip, sehingga membingungkan baik pemerintah desa maupun masyarakatnya.

2. Keberlanjutan

Pengembangan PBBM di suatu wilayah baik oleh instansi Pemerintah maupun oleh organisasi swasta sangat efektif dan bermanfaat, terutama pada saat terjadi bencana dan tahap rehabilitasi dan rekonstruksi atau pada awal-awal pembentukan organisasi ini. Namun seringkali keberlanjutanya kurang diperhatikan baik oleh organisasi pembentuk maupun oleh pemerintah Desa/Kelurahan setempat. Misalnya program-program sosialisasi, pelatihan, pembinaan lanjut atau FGD rutin seringkali tidak lagi dilakukan. Dan organisasiorganisasi PBBM di tingkat Desa/Kelurahan banyak yang mati suri.

3. Pendanaan

Masalah klasik dari berjalannya suatu kegiatan adalah masalah pendanaan. Dana yang disediakan oleh fihak pengembang PBBM seringkali hanya ada pada saat pembentukan. Sebagian besar pemerintah Desa/kelurahan tidak bersedia untuk mengeluarkan anggaran rutin untuk kegiatan organisasi PBBM.

\section{SIMPULAN}

Kesimpulan yang dapat diambil dari analisis di atas adalah:

1. Pengelolaan Bencana Berbasis Masyarakat (PBBM) sangat penting karena merupakan salah satu "soko guru" atau pilar dalam pengurangan risiko bencana.

2. Di Indonesia sudah banyak berkembang dan dikembangkan PBBM, namun agar dapat bekerja secara efektif perlu perhatian dari berbagai fihak baik Pemerintah maupun organisasi swasta untuk keberlanjutanya.

\section{DAFTAR PUSTAKA}

Haque, C. E., \& Uddin, M. S. (2013). Disaster management discourse in Bangladesh: A shift from post-event response to the preparedness and mitigation approach through institutional partnerships. In J. Tiefenbacher (Eds.), Approaches to disaster management: Examining the implications of hazards, emergencies and disasters (pp. 33-44). London: IntechOpen.

Handayani, R. (2011). Analisis Partisipasi Masyarakat Dan Peran Pemerintah Daerah Dalam Pelaksanaan Manajemen Bencana Di Kabupaten 
Serang Provinsi Banten. Proceeding Simposium Nasional Otonomi Daerah. Serang, Jawa Barat.

Keputusan Kepala Badan Nasional Penanggulangan Bencana Nomor 5 tahun 2010 tentang Rencana Aksi Nasional Pengurangan Risiko Bencana (RAN-PRB) tahun 2010.

Luna, E. M. (2014). Community-based disaster risk reduction and disaster management. In A. Lopez-Carresi, M. Fordham, I. Kelman \& J. C. Gaillard (Eds.), Disaster management international lessons in risk reduction, response and recovery. Oxon: Routledge.

M S S Ali, M Arsyad, A Kamaluddin, N Busthanul, and A Dirpan, (2018), Community based disaster management: Indonesian experience, IOP Conf. Series: Earth and Environmental Science 235 (2019) 012012.

Pandey, B and Okazaki, K, 2005, Community Based Disaster Management: Empowering Communities to Cope with Disaster Risks, https://www.researchgate.net/publication/237783698.

Paripurno, Eko Teguh. 2006. Penanggulangan Bencana oleh Komunitas. Yogyakarta: Pusat Studi Manajemen Bencana UPN Veteran Yogyakarta

Paripurna, ET dan Jannah NM, (2014), Panduan Pengelolaan Risiko Bencana Berbasis Komunitas (PRBBK), Deepublish, Yogyakarta

Peraturan Badan Nasional Penanggulangan Bencana No. 13 Tahun 2010 tentang Rencana Nasional Penanggulangan Bencana (Renas-PB) 2010-2014.

Peraturan Kepala BNPB Nomor 1 tahun 2012 tentang Pedoman Umum Desa/kelurahan Tangguh Bencana.

Peraturan Menteri Sosial Republik Indonesia Nomor 128 tahun 2011 tentang Kampung Siaga Bencana.

Twigg J. 2006. "Disaster Early Warning Systems: People, Politics and Economics." Benfield Hazard Research Centre Disaster Studies, Working Paper 16

Undang-Undang Nomor 24 Tahun 2007 tentang Penanggulangan Bencana.

United Nations Office for Disaster Risk Reduction (UNISDR). (2007). Hyogo Framework for action 2005-2015: Building the resilience of nations and communities to disasters. Retrieved from https://www.unisdr.org/files/1037 hyogoframeworkforactionenglish.pdf

Urry, J. (2011). Climate change and society. Cambridge: Polity Press. Van Voorst, R. (2016).

Yodmani, S. (2001). Disaster risk management and vulnerability reduction: Protecting the poor. Paper Presented at The Asia and Pacific Forum on Poverty. Asian Disaster Preparedness Centre, Bangkok (pp. vi, 32). Retrieved from http://www.adpc.net/

V2007/IKM/ONLINE\%20DOCUMENTS/downloads/PovertyPaper.pdf 